\title{
Association of Socio-Demographic and Clinicopathological Risk Factors with Oral Cancers: A 19-Year Retrospective Study
}

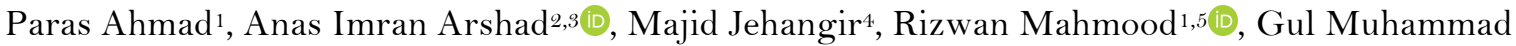

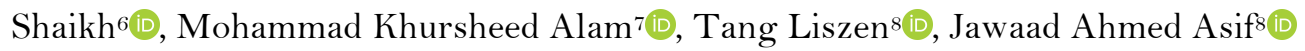

\begin{abstract}
'Oral Medicine Unit, School of Dental Sciences, Universiti Sains Malayia, Kelantan, Malaysia.
2Paediatric Dentistry Unit, School of Dental Sciences, Universiti Sains Malaysia, Kota Bharu, Kelantan, Malaysia.

${ }^{3}$ Paedodontics Department, Rashid Latif Dental College, Rashid Latif Medical College, Lahore, Pakistan.

${ }^{4}$ Department of Oral Pathology, Azra Naheed Dental College, Superior University, Lahore, Pakistan.

${ }^{5}$ Department of Oral Medicine, Azra Naheed Dental College, Superior University, Lahore, Pakistan.

${ }^{6}$ Health Professions Education, National University of Medical Sciences, Rawalpindi, Pakistan.

${ }^{7}$ Orthodontic Department, College of Dentistry, Jouf University, Sakaka, Saudi Arabia.

${ }^{8}$ Department of Oral and Maxillofacial Surgery, School of Dental Sciences, Universiti Sains Malaysia, Kota Bharu, Kelantan, Malaysia.
\end{abstract}

Correspondence: Jawaad Ahmed Asif, Department of Oral and Maxillofacial Surgery, School of Dental Sciences, Universiti Sains Malaysia, 16150 Kubang Kerian, Kota Bharu, Kelantan, Malaysia. E-mail: dentistjawaad@gmail.com

Academic Editor: Wilton Wilney Nascimento Padilha

Received: 06 March 2020 / Review: 22 July 2020 / Accepted: 29 August 2020

How to cite: Ahmad P, Arshad AI, Jehangir M, Mahmood R, Shaikh GM, Alam MK, et al. Association of sociodemographic and clinicopathological risk factors with oral cancers: a 19-year retrospective study. Pesqui Bras Odontopediatria Clín Integr. 202 1; 21:e0037. https://doi.org/10.1590/pboci.2021.010

\begin{abstract}
Objective: To determine the association of socio-demographic and clinic-pathological risk factors with oral cancer in Kelantan, Malaysia. Material and Methods: A 19-year cross-sectional survey was performed in Hospital Universiti Sains Malaysia (HUSM), Malaysia. Medical record of 301 oral cancer patients was retrieved from the Medical Records office. Results: The majority of the oral cancer cases were male (62.8\%), non-smokers $(57.5 \%)$, non-alcohol consumers (83.4\%), non-betel quid chewers $(96.7 \%)$, and belonged to Malay ethnicity (68.8\%). At the time of diagnosis, most of the patients were at stage II (38.9\%). Approximately one-third (30.6\%) of the total OC patients experienced loco-regional/distant metastasis, whereas no metastasis was detected in around two-thirds of cases (69.4\%). A combination of surgery and radiotherapy was the most commonly employed treatment modality $(27.2 \%)$. At the time of this study, the survival status of most of the patients was alive $(69.1 \%)$. The most frequently encountered oral cancer in the Kelantanese population was oral squamous cell carcinoma $(70.1 \%)$, with the tongue being the most frequently involved oral cavity site (35.5\%). Conclusion: More than three-fourths of the cases were alive at follow-up, which included the cases that did not undergo any form of treatment.
\end{abstract}

Keywords: Mouth Neoplasms; Carcinoma, Squamous Cell; Tongue Neoplasms; Salivary Gland Neoplasms. 


\section{Introduction}

Globally, cancer is a disease of great concern due to its incidence and mortality [1]. According to the World Health Organization (WHO), by 2030, approximately 75 million individuals will be having cancer [2]. Oral cancer (OC) is one of the ten most commonly occurring cancers worldwide and it is attributed as the leading cause of death in certain geographical regions such as South-Central Asia [3]. It was estimated that in 2018, 407,600 people were affected by OC globally; approximately half of whom $(199,560)$ died of the disease. Unfortunately, around two-thirds of these cases were reported in developing countries [4].

There is a wide disparity in the prevalence of OC by geographical area and sex [5]. Variations have been recognized at the molecular level and the clinic-pathological behavior in alcohol-associated and tobaccosmoking OC in Japan, United States (US), France, United Kingdom, as well as tobacco-chewing oral carcinomas in Southeast Asia [6]. In Malaysia, the Indian race was detected to have a higher risk of OC than Malays and Chinese [7].

Studies report that men over 50 years of age are at an increased risk of developing OC $[1,8] .85 \%$ of $\mathrm{OC}$ in women and $93 \%$ of $\mathrm{OC}$ in men are determined by lifestyle factors such as tobacco smoking, betel quid chewing, alcohol intake, the presence of pre-malignant lesions, etc. [9].

Oral squamous cell carcinoma (OSCC) is the most commonly encountered histological type (90\%) of OC [8]. Posterior-lateral border and ventral surfaces of the tongue are the most frequently involved sites in tongue cancers, followed by the mouth floor. Relatively less common intra-oral sites are gingiva, hard palate, buccal and labial mucosa [10]. The site of the primary tumor occurrence, the tumor size (T stage), nodal metastasis (N stage) and extra-capsular spread of the primary tumor dictates the treatment modality chemotherapy (CT), radiotherapy (RT), surgery, or a combination [11]. The OC's successful treatment outcome depends on the appropriate management of both the loco-regional lymphatics and the primary site $[11]$.

This study aimed to determine the association of socio-demographic and clinic-pathological risk factors with oral cancers in Kelantan, Malaysia.

\section{Material and Methods}

Study Design and Sample

This was a retrospective cross-sectional study that comprised a collection of 301 OC patients' sociodemographic data, clinicopathological feature data, type and treatment modalities. The study site was Hospital Universiti Sains Malaysia (HUSM), Kelantan, which is located in northeastern Peninsular Malaysia. The required data were obtained from the medical record office of HUSM between January 2000 and December 2018.

\section{Data Collection}

The registration numbers of patients were retrieved from a computerized database search for all OC patients in the Records Unit of HUSM, and the histopathology reports were cross-examined from the archives of Oral Pathology Laboratory of HUSM. Few records of patients diagnosed with OC were retrieved from Oral Pathology Laboratory archives at the School of Dental Sciences, USM. A standardized data collection proforma was used to collect the relevant data of the patients. Records with missing information were excluded. 


\section{Data Analysis}

Statistical Package for the Social Sciences (SPSS version 24.0 IBM, Armonk, NY: IBM Corp, USA) was used for data analysis. To calculate the absolute and relative frequencies, descriptive statistics were used.

Ethical Aspects

Human Ethics and Committee Universiti Sains Malaysia (USM) granted ethical approval. This research was performed in conformity with the Jawatankuasa Etika Penyeldikan (Manusia), USM, Malaysia (JEPeM code - USM/JEPeM/18100613).

\section{Results}

A total of 368 OC cases were registered. Of these, 301 cases were included. Sixty-seven OC cases were excluded due to missing and/or lost data in medical records. The final analysis was done on the data of 301 patients.

\section{Socio-Demographic Features}

The mean age was 55 years. Most of the participants were male (62.8\%), non-smoker (57.5\%), nonalcohol consumer (83.4\%) and non-betel quid chewer (96.7\%) and Malay (68.8\%) (Table 1).

Table 1. Socio-demographic features of oral cancer patients.

\begin{tabular}{lc}
\hline \multicolumn{1}{c}{ Variables } & $\mathbf{N}(\%)$ \\
\hline Age (in Years) & $55.0($ Mean) \\
Gender & \\
Male & $189(62.8)$ \\
Female & $112(37.2)$ \\
Ethnicity & $207(68.8)$ \\
$\quad$ Malay & $63(20.9)$ \\
Indian & $31(10.3)$ \\
Chinese & $128(42.5)$ \\
Tobacco Consumption & $173(57.5)$ \\
$\quad$ Smoker & \\
Non-Smoker & $50(16.6)$ \\
Alcohol Intake & $251(83.4)$ \\
User & \\
Non-User & $10(3.3)$ \\
Betel Quid Use & $291(96.7)$ \\
User & \\
Non-User & $69(22.9)$ \\
Past Family History of Tumor & $232(77.1)$ \\
Yes & \\
No & $63(20.9)$ \\
HPV Predisposing Factors & $238(79.1)$ \\
Yes & \\
No &
\end{tabular}

The majority of the cases were diagnosed as stage II at the time of diagnosis (38.9\%). A total of $30.6 \%$ of patients experienced loco-regional/distant metastasis, whereas no metastasis was detected in $69.4 \%$. The majority of the patients received a combination of surgery and RT as the mode of treatment (27.2\%). When this study was performed, the survival status of the majority of the patients was alive (69.1\%) (Table 2).

Oral squamous cell carcinoma was the most frequently encountered OC in the Kelantanese population (70.1\%), followed by mucoepidermoid carcinoma (8.3\%) and adenoid cystic carcinoma (5.6\%) (Table 3). 
Table 2. Clinicopathological features of oral cancer patients.

\begin{tabular}{lc}
\hline \multicolumn{1}{c}{ Variables } & $\mathbf{N}(\%)$ \\
\hline T Classification & $37(12.3)$ \\
T1 & $117(38.9)$ \\
T2 & $48(15.9)$ \\
T3 & $99(32.9)$ \\
T4a, T4b, T4c & \\
N Classification & $42(13.9)$ \\
No & $75(24.9)$ \\
N1 & $138(45.8)$ \\
N2a, N2b, N2c & $46(15.4)$ \\
N3 & \\
M Classification & $209(69.4)$ \\
Mo & $92(30.6)$ \\
M1 & \\
TNM Staging & $27(9.0)$ \\
Stage I & $38(12.6)$ \\
Stage II & $96(31.9)$ \\
Stage III & $140(46.5)$ \\
Stage IVa, IVb, IVc & \\
Treatment & $43(14.3)$ \\
Surgery & $20(6.6)$ \\
Surgery + Chemotherapy & $82(27.2)$ \\
Surgery + Radiotherapy & $28(9.3)$ \\
Surgery + Chemotherapy + Radiotherapy & $50(16.6)$ \\
Radiotherapy & $22(7.3)$ \\
Radiotherapy + Chemotherapy & $16(5.3)$ \\
Chemotherapy & $40(13.3)$ \\
No Treatment & \\
Survival Status & $208(69.1)$ \\
Alive & $93(30.9)$ \\
Dead & \\
\hline
\end{tabular}

Table 3. Types of oral cancers of different histopathological origins.

\begin{tabular}{ccc}
\hline Histopathological Origin & Site Distribution & N (\%) \\
\hline Epithelial Origin $(\mathbf{N} / \%)$ & Tongue & $98(46.4)$ \\
Squamous Cell Carcinoma $(211 / 70.1 \%)$ & Anterior Tongue & 61 \\
& Posterior Tongue & 37 \\
& Buccal Mucosa & $33(15.6)$ \\
& Floor of Mouth & $22(10.4)$ \\
& Sinus & $17(8.0)$ \\
& Nasal Sinus & 8 \\
& Maxillary Sinus & 5 \\
& Paranasal Sinus & 2 \\
& Sphenoidal Sinus & 2 \\
& Alveolus & $12(5.7)$ \\
& Upper Alveolus & 3 \\
Basal Cell Carcinoma $(6 / 2.0)$ & Lower Alveolus & 9 \\
& Gland & $12(5.7)$ \\
& Parotid Gland & 8 \\
& Submandibular Gland & 4 \\
& Lip & $10(4.7)$ \\
& Upper Lip & 7 \\
& Lower Lip & 3 \\
& Hard Palate & $7(3.3)$ \\
& Lip & $4(66.7)$ \\
& Lower Lip & 4
\end{tabular}




\begin{tabular}{|c|c|c|}
\hline & Gland & $2(33.3)$ \\
\hline & Parotid Gland & 1 \\
\hline & Submandibular Gland & 1 \\
\hline \multirow{5}{*}{ Basaloid Squamous Cell Carcinoma (4 / 1.3) } & Floor of Mouth & $2(50.0)$ \\
\hline & Tongue & $1(25.0)$ \\
\hline & Anterior Tongue & 1 \\
\hline & Gland & $1(25.0)$ \\
\hline & Parotid Gland & 1 \\
\hline \multirow[t]{4}{*}{ Malignant Melanoma (3/1.0) } & Palate & $2(75.0)$ \\
\hline & Hard Palate & 2 \\
\hline & Alveolus & $1(25.0)$ \\
\hline & Lower Alveolus & 1 \\
\hline \multicolumn{3}{|l|}{ Glandular Origin } \\
\hline \multirow{9}{*}{ Mucoepidermoid Carcinoma (25 / 8.3) } & Gland & $15(60.0)$ \\
\hline & Parotid Gland & 14 \\
\hline & Submandibular Gland & 1 \\
\hline & Palate & $6(24.0)$ \\
\hline & Hard Palate & 5 \\
\hline & Soft Palate & 1 \\
\hline & Floor of Mouth & $3(12.0)$ \\
\hline & Alveolus & $1(4.0)$ \\
\hline & Upper Alveolus & 1 \\
\hline \multirow[t]{8}{*}{ Adenoid Cystic Carcinoma (17 / 5.6) } & Gland & $12(70.6)$ \\
\hline & Submandibular Gland & 7 \\
\hline & Parotid Gland & 5 \\
\hline & Buccal Mucosa & $3(17.6)$ \\
\hline & Tongue & $1(5.9)$ \\
\hline & Anterior Tongue & 1 \\
\hline & Sinus & $1(5.9)$ \\
\hline & Sphenoidal Sinus & 1 \\
\hline \multirow[t]{7}{*}{ Adenocarcinoma (7 / 2.3$)$} & Gland & $5(71.4)$ \\
\hline & Parotid Gland & 3 \\
\hline & Submandibular Gland & 2 \\
\hline & Lip & $1(14.3)$ \\
\hline & Lower Lip & 1 \\
\hline & Sinus & $1(14.3)$ \\
\hline & Nasal Sinus & 1 \\
\hline \multirow[t]{2}{*}{ Acinic Cell Carcinoma ( $3 / 1.0)$} & Gland & $3(100.0)$ \\
\hline & Parotid Gland & 3 \\
\hline \multicolumn{3}{|l|}{ Mesenchymal Origin } \\
\hline \multirow[t]{7}{*}{ Rhabdomyosarcoma $(6$ / 2.0) } & Buccal Mucosa & $3(50.0)$ \\
\hline & Alveolus & $1(16.7)$ \\
\hline & Lower Alveolus & 1 \\
\hline & Lip & $1(16.66 \%)$ \\
\hline & Lower Lip & 1 \\
\hline & Gland & $1(16.7)$ \\
\hline & Submandibular Gland & 1 \\
\hline \multirow[t]{6}{*}{ Leiomyosarcoma (4 / 1.3) } & Tongue & $2(50.0)$ \\
\hline & Anterior Tongue & 2 \\
\hline & Lip & $1(25.0)$ \\
\hline & Lower Lip & 1 \\
\hline & Palate & $1(25.0)$ \\
\hline & Hard Palate & 1 \\
\hline \multirow[t]{4}{*}{ Angiosarcoma (3 / 1.0) } & Tongue & $2(66.7)$ \\
\hline & Anterior Tongue & 2 \\
\hline & Gland & $1(33.3)$ \\
\hline & Parotid Gland & 1 \\
\hline \multirow[t]{3}{*}{ B-cell lymphoma (3 / 1.0) } & Tongue & $3(100.0)$ \\
\hline & Anterior Tongue & 2 \\
\hline & Posterior Tongue & 1 \\
\hline
\end{tabular}




\begin{tabular}{|c|c|c|}
\hline Osteosarcoma (3 / 1.0) & Palate & $3(100.0)$ \\
\hline & Hard Palate & 3 \\
\hline \multirow[t]{4}{*}{ Pleomorphic sarcoma (2 / 0.7) } & Palate & $1(50.0)$ \\
\hline & Hard Palate & 1 \\
\hline & Sinus & $1(50.0)$ \\
\hline & Nasal Sinus & 1 \\
\hline \multicolumn{3}{|l|}{ Mixed/Other Origins } \\
\hline \multirow[t]{4}{*}{ Lymphoepithelial Carcinoma (4 / 1.3) } & Gland & $3(75.0)$ \\
\hline & Parotid Gland & 3 \\
\hline & Lip & $1(25.0)$ \\
\hline & Upper Lip & 1 \\
\hline
\end{tabular}

The tongue was the most commonly involved part of the oral cavity with OC (35.5\%), followed by major salivary glands, including the parotid gland and submandibular gland (18.3\%) and buccal mucosa $(13.0 \%)($ Table 4$)$.

Table 4. Data distribution based on site of oral cancer.

\begin{tabular}{cc}
\hline \multicolumn{1}{c}{ Cancer Site } & $\mathbf{N}(\%)$ \\
\hline Tongue & $107(35.5)$ \\
Anterior & 69 \\
Posterior & 38 \\
Buccal Mucosa & $39(13.0)$ \\
Floor of Mouth & $27(9.0)$ \\
Gingiva & $15(5.0)$ \\
Upper Gingiva & 4 \\
Lower Gingiva & 11 \\
Lips & $18(6.0)$ \\
Upper Lip & 8 \\
Lower Lip & 10 \\
Glands & $55(18.3)$ \\
Parotid Gland & 39 \\
Submandibular Gland & 16 \\
Palate & $20(6.6)$ \\
Hard Palate & 19 \\
Soft Palate & 1 \\
Sinuses & $20(6.6)$ \\
Nasal Sinus & 10 \\
Paranasal Sinus & 2 \\
Sphenoid Sinus & 3 \\
Maxillary Sinus & 5 \\
\hline
\end{tabular}

In the 19-year period (2000-2018), 86.7\% patients had received treatment, while $13.3 \%$ did not receive any treatment. A total of $74.7 \%$ of patients who had undergone treatment lived, while $67.5 \%$ who did not receive any treatment died (Table 5).

Table 5. Status of treatment outcome in oral cancer patients.

\begin{tabular}{|c|c|c|c|}
\hline \multicolumn{4}{|c|}{ Treatment Outcome Status } \\
\hline Treatment & $\begin{array}{c}\text { Alive } \\
(\mathrm{N} / \%)\end{array}$ & $\begin{array}{c}\text { Dead } \\
(\mathrm{N} / \%)\end{array}$ & $\begin{array}{c}\text { Total } \\
(\mathrm{N} / \%)\end{array}$ \\
\hline Yes & $195(74.7)$ & $66(25.3)$ & $261(86.7)$ \\
\hline No & $13(32.5)$ & $27(67.5)$ & $40(13.3)$ \\
\hline Total & $208(69.1)$ & $93(30.9)$ & $301(100.0)$ \\
\hline
\end{tabular}

\section{Discussion}


Improvement of disease control is largely dependent on identifying risk factors and the epidemiology of that specific disease. Provisions of symptomatic treatment to cancer patients fail to help the cancer control strategies. The current study determined the types of OCs reported since the year 2000 in Hospital Universiti Sains Malaysia, located in Kelantan, Malaysia. This study also explored the association of OC with sociodemographic and clinic-pathological risk factors.

Globally, it has been well reported that the incidence of OC escalates with increasing age. Individuals above forty years of age are at peak risk for developing OC [12]. The mean age of 55 years was determined in the present study, which is in accordance with the data from Yemen, Pakistan, and a multi-center study $[5,12,13]$. The occurrence of OSCC was commonly observed in the sixth decade of life, which has been reported in several studies [13-17]. Several histopathological origins, including epithelial, glandular, and mesenchymal, were reported to commonly occur at different times [17]. According to gender, male cases were common than females, with a male ratio of 1.68 to 1 . Our data's gender distribution was comparable with the Pakistani and African population [13,17]; however, the male predilection was observed up to 4.3:1 in multicenter studies involving larger sample data [12,16]. These findings are in accordance with multiple studies conducted to associate the age [13-16] and gender factors [15,17-20] with the increasing risk of developing OC.

We found that $70.1 \%$ of cases in this study had OSCC. Oral squamous cell carcinoma has been identified as the most commonly occurring malignant tumor of the oral cavity [1,13-15,17]. Several studies described their results by dividing the malignancies into different regions such as oropharynx, oral cavity, pharynx, and larynx $[5,12,13]$. The present study presented the data distribution based on the site of the tumor; and that within the oral cavity, the tongue was the most common tumor site, which is in accordance with several other studies $[5,12,13]$ and in agreement with global epidemiology data that reported tongue as the most "cancer-prone" intra-oral site in most populations [21]. The site distribution was different in this study as compared with other studies conducted in other Asian countries, whereby the most frequent site of OSCC was buccal mucosa. This might be due to the habitual practice of placing betel quid between teeth and buccal mucosa, as commonly observed in populations of India, Myanmar, Thailand, and Taiwan [22]. In Malaysia and Indonesia, betel quid chewing habit has been primarily replaced with smoking since early to mid1990s [23]. The second most common tumor site within the oral cavity included parotid and submandibular glands, which was also found to be in opposition to several other studies [12,18-20].

The present study's findings are in accordance with the TNM classification recommended for classifying malignant tumors [22]. The highest number of subjects presented with the T2 stage closely followed by the T4 stage, whereas Mendez et al. [8] reported most cases with the T4 stage. $69 \%$ of the present study cases were alive at follow-up, which included the cases that did not undergo any form of treatment. The majority of patients presenting at the T4 stage were not surgically operated, explaining the high incidence of cases receiving no treatment. We identified that different studies described their results based on different classification systems, histopathology [15], nature of the tumor (benign or malignant) [14], site of the tumor [18], grading of differentiation [13] and involved region [5,12].

In the present study, the majority of the patients received a combination of surgery and RT. This finding coincides with the guidelines of the National Comprehensive Cancer Network (NCCN). According to NCCN, the standard of care for early-stage resectable (T1/T2) OSCC is surgery and/or RT; the majority of surgeons give preference to primary resection with or without elective neck dissection [24]. For early-stage disease, equivalent loco-regional control rates can be obtained in comparison to surgery; however, RT requires 
both external beam and brachytherapy to be used together [25]. There is no robust prospective study comparing the 2 modalities against one another, but a single case series demonstrated superior loco-regional control with definitive surgical resection compared to definitive RT for early-stage OC [26]. However, previous authors pointed out that these patients received less intense treatment protocols than those recommended today [27]. Huang et al. performed a retrospective study of 148 patients with T1/T2, No disease, and documented clear margins after definitive surgical resection with $>90 \%$ loco-regional control $[28]$.

The RT by itself may be offered to patients with unresectable disease, the recurrent disease not amenable to further resection, patients who refuse surgery or are deemed too medically unstable for surgery (ie, significant comorbidities, poor functional status), as well as patients in whom RT is determined to avoid significant functional/cosmetic disability [27,29]. The advantage of surgical resection over RT may be several-fold; RT has sequelae that can significantly impact the quality of life, including xerostomia, dysphagia, and osteoradionecrosis [29]. Moreover, the treatment course can be close to 2 months, whereas surgical treatment of early OSCC has a quicker recovery [29]. In general, oral cavity cancers are best treated with surgery, whereas definitive RT should only be used if surgery is unable to be performed or is refused by the patient.

The future recommendation includes that emphasis should be made to follow guidelines designed to standardize the screening and reporting of any observational study to perform comparative studies in different populations. The importance of the development of a consensus of the ontology of oral cancers is also stressed upon. This would ease the process of systematic searching of the available literature with the elimination of potential bias. A countrywide screening of potential cancer risk in different public and private tertiary care centers will facilitate in establishing cancer control and will play a pivotal role in spreading awareness of this disease. This report will serve as a database of the OC burden in Northeastern Peninsular Malaysia.

\section{Conclusion}

Despite the presence of a high incidence of metastasis and a high proportion of cases who did not receive any form of treatment, around three-fourth of the total oral cancer patients were alive at the time of this study.

\section{Authors' Contributions}

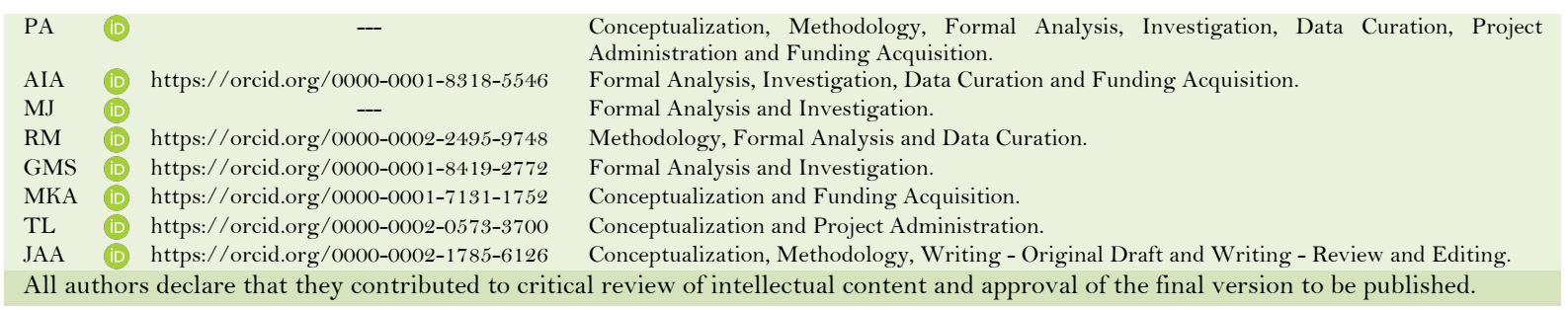

\section{Financial Support}

The second author (A.I.A) is grateful to the university for providing financial assistance under fellowship scheme for 2 years of his candidature. All authors acknowledge the sponsorship of article publication charges from the Universiti Sains Malaysia RU (Grant No. 1001/PPSG/812079).

\section{Conflict of Interest}

The authors declare no conflicts of interest. 


\section{Data Availability}

The data used to support the findings of this study can be made available upon request to the corresponding author.

\section{References}

[1] Dantas TS, de Barros Silva PG, Sousa EF, da Cunha Mdo P, de Aguiar AS, Costa FW, et al. Influence of educational level, stage, and histological type on survival of oral cancer in a Brazilian population: a Retrospective Study of 10 Years Observation. Medicine 2016; 95(3):e2314. https://doi.org/10.1097/MD.0000000000002314

[2] Facina T. Estimate 2014 - cancer incidence in Brazil. Rev Bras Cancerol 2014; 60(1):63-4. https://doi.org/10.32635/2176-9745.RBC.2014v60n 1.964

[3] McDonald JT, Johnson-Obaseki S, Hwang E, Connell C, Corsten M. The relationship between survival and socioeconomic status for head and neck cancer in Canada. J Otolaryngol Head Neck Surg 2014; 43(1):2. https://doi.org/10.1186/1916-02 16-43-2

[4] Bray F, Ferlay J, Soerjomataram I, Siegel RL, Torre LA, Jemal A. Global cancer statistics 2018: GLOBOCAN estimates of incidence and mortality worldwide for 36 cancers in 185 countries. CA Cancer J Clin 2018; 68(6):394424. https://doi.org/10.3322/caac.2 1492

[5] Halboub ES, Abdulhuq M, Al-Mandili A. Oral and pharyngeal cancers in Yemen: a retrospective study. East Mediterr Health J 2012; 18(9):985-91. https://doi.org/10.26719/2012.18.9.985

[6] Kumar M, Nanavati R, Modi TG, Dobariya C. Oral cancer: Etiology and risk factors: A review. J Cancer Res Ther 2016; 12(2):458-63. https://doi.org/10.4103/0973-1482.186696

[7] Zain RB, Ghazali N. A review of epidemiological studies of oral cancer and precancer in Malaysia. Ann Dent 2001; 8(1):50-6. https://doi.org/10.22452/adum.vol8no1.9

[8] Mendez M, Carrard VC, Haas AN, Lauxen IdS, Barbachan JJD, Rados PV, et al. A 10-year study of specimens submitted to oral pathology laboratory analysis: lesion occurrence and demographic features. Braz Oral Res 2012; 26(3):235-41. https://doi.org/10.1590/S1806-83242012000300009

[9] Crăcană A, Şulea D, Nicolau A, Popa E, Popescu E. Risk factors in the emergence of oral cancer - retrospective study. Roman J Oral Rehabil 2016; 8(3):48-63.

[10] Zini A, Czerninski R, Sgan-Cohen HD. Oral cancer over four decades: epidemiology, trends, histology, and survival by anatomical sites. J Oral Pathol Med 2010; 39(4):299-305. https://doi.org/10.1111/j.1600-0714.2009.00845.x

[11] Gupta B, Johnson NW. Oral cancer: Indian pandemic. Br Dent J 2017; $222(7): 497$. https://doi.org/10.1038/sj.bdj.2017.293

[12] Warnakulasuriya S. Living with oral cancer: epidemiology with particular reference to prevalence and life-style changes that influence survival. Oral Oncol 2010; 46(6):407-10. https://doi.org/10.1016/j.oraloncology.2010.02.015

[13] Mehrotra R, Singh M, Kumar D, Pandey A, Gupta R, Sinha U. Age specific incidence rate and pathological spectrum of oral cancer in Allahabad. Indian J Med Sci 2003; 57(9):400-4.

[14] Horowitz AM, Nourjah PA. Factors associated with having oral cancer examinations among US adults 40 years of age or older. J Public Health Dent 1996; 56(6):331-5. https://doi.org/10.1111/j.1752-7325.1996.tbo2460.x

[15] Chen YK, Huang HC, Lin LM, Lin CC. Primary oral squamous cell carcinoma: an analysis of 703 cases in southern Taiwan. Oral Oncol 1999; 35(2):173-9. https://doi.org/10.1016/s1368-8375(98)00101-8

[16] Goldenberg D, Brooksby C, Hollenbeak CS. Age as a determinant of outcomes for patients with oral cancer. Oral Oncol 2009; 45(8):e57-61. https://doi.org/10.1016/j.oraloncology.2009.01.011

[17] Honorato J, Rebelo MS, Dias FL, Camisasca DR, Faria PA, Azevedo e Silva G, et al. Gender differences in prognostic factors for oral cancer. Int J Oral Maxillofac Surg 2015; 44(10):1205-11. https://doi.org/10.1016/j.ijom.2015.04.015

[18] Khammissa RA, Meer S, Lemmer J, Feller L. Oral squamous cell carcinoma in a South African sample: Race/ethnicity, age, gender, and degree of histopathological differentiation. J Cancer Res Ther 2014; 10(4):908-14. https://doi.org/10.4103/0973-1482.138100

[19] Kruse AL, Bredell M, Grätz KW. Oral cancer in men and women: are there differences? Oral Maxillofac Surg 2011; 15(1):51-5. https://doi.org/10.1007/s 10006-010-0253-6

[20] Razak AA, Saddki N, Naing NN, Abdullah N. Oral cancer survival among Malay patients in Hospital Universiti Sains Malaysia, Kelantan. Asian Pac J Cancer Prev 2010; 11(1):187-91.

[21] Moore SR, Johnson NW, Pierce AM, Wilson DF. The epidemiology of tongue cancer: a review of global incidence. Oral Dis 2000; 6(2):75-84. https://doi.org/10.1111/j.1601-0825.2000.tb00105.x

[22] Moore SR, Johnson NW, Pierce AM, Wilson DF. The epidemiology of mouth cancer: a review of global incidence. Oral Dis 2000; 6(2):65-74. https://doi.org/10.1111/j.1601-0825.2000.tbo0104.x

[23] Achadi A, Soerojo W, Barber S. The relevance and prospects of advancing tobacco control in Indonesia. Health Policy 2005; 72(3):333-49. https://doi.org/10.1016/j.healthpol.2004.09.009

[24] Marur S, Forastiere AA. Head and neck squamous cell carcinoma: update on epidemiology, diagnosis, and treatment. Mayo Clin Proc 2016; 91(3):386-96. https://doi.org/10.1016/j.mayocp.2015.12.017

[25] Delclos L, Lindberg RD, Fletcher GH. Squamous cell carcinoma of the oral tongue and floor of mouth. Evaluation of interstitial radium therapy. AJR Am J Roentgenol 1976; 126(2):223-8. https://doi.org/10.22 14/ajr.126.2.223 
[26] Studer G, Zwahlen RA, Graetz KW, Davis BJ, Glanzmann C. IMRT in oral cavity cancer. Radiat Oncol 2007; 2(1):16-22. https://doi.org/10.1186/1748-717X-2-16

[27] Huang SH, O'Sullivan B. Oral cancer: Current role of radiotherapy and chemotherapy. Med Oral Patol Oral Cir Bucal 2013; 18(2):e233-40. https://doi.org/10.4317/medoral. 18772

[28] Huang T-Y, Hsu L-P, Wen Y-H, Huang T-T, Chou Y-F, Lee C-F, et al. Predictors of locoregional recurrence in early stage oral cavity cancer with free surgical margins. Oral Oncol 2010; 46(1):49-55. https://doi.org/10.1016/j.oraloncology.2009.10.011

[29] Genden EM, Ferlito A, Silver CE, Takes RP, Suárez C, Owen RP, et al. Contemporary management of cancer of the oral cavity. Eur Arch Otorhinolaryngol 2010; 267(7):1001-17. https://doi.org/10.1007/s00405-010-1206-2 